\title{
FAKTOR-FAKTOR YANG BERHUBUNGAN DENGAN SIKAP REMAJA KELAS XI TERHADAP HUBUNGAN SEKSUAL PRANIKAH (INTERCOURSE) DI SMA DHARMA BAKTI MEDAN TAHUN 2014
}

\author{
Hanna Sriyanti Saragih, Rika Dinata Sianturi, Jujuren Sitepu \\ Jurusan Kebidanan Poltekkes Kemenkes Medan
}

\begin{abstract}
The lack of information received by adolescents about reproductive health and lack of knowledge causes an effect on adolescent attitudes toward sexual behavior. Destination of the research for factors associated with adolescent attitudes toward class xi premarital sexual relations (intercourse) Medan of Dharma Bakti Senior High School year 2014. The role of parents also influence adolescent attitudes toward premarital sexual relations. Additionally teenagers often receive information about sex instead of one source, even misleading, for example, of the mass media that actually abused by teens. This research is analytic approach to crosssectional design with a sample size of 60 respondents. Data were analyzed using univariate and bivariate Chi-Square test. The analysis showed that factors associated with adolescent attitudes toward premarital sexual intercourse in high school is Dharma Bakti field of reproductive health knowledge $p$ value $=0,005$ $(<0,05)$, the role of parents $p$ value $=0,001(<0,05)$, the role of the mass media $p$ value $=0,010(<0,05)$. It is expected that the school can make this research as a guide to improve the provision of information or education about reproductive health especially about sex education for adolescent in school.
\end{abstract}

Keywords : Attitude, intercourse

\section{PENDAHULUAN}

\section{Latar Belakang}

Remaja merupakan populasi yang terbesar dari penduduk dunia. Menurut World Health Organization (WHO) sekitar seperlima dari penduduk dunia adalah remaja berusia 10-19 tahun. Sekitar 900 juta berada di negara berkembang. Di Indonesia pada tahun 2007 jumlah remaja usia 10-24 tahun terdapat sekitar 64 juta atau 28,64\% dari jumlah penduduk Indonesia (Muadz, dkk, 2008).

Menurut Depkes tahun 2007 menunjukkan bahwa kegiatan seks bebas menempatkan remaja pada tantangan risiko yang berat terhadap berbagai masalah kesehatan reproduksi. Setiap tahun kira-kira 15 juta remaja berusia 15-19 tahun melahirkan anak, 4 juta melakukan aborsi, dan hampir 100 juta terinfeksi Penyakit Menular Seksual (PMS) yang masih dapat disembuhkan (Dwi Novita, 2011).

Perilaku seks pranikah dapat mengakibatkan risiko, seperti terjadinya kehamilan yang tidak diinginkan (KTD), putus sekolah (drop out), jika remaja tersebut masih sekolah dapat melakukan pengguguran kandungan (aborsi), terkena penyakit menular seksual (PMS), dan tekanan psikososial yang timbul karena perasaan bersalah telah melanggar aturan agama dan takut diketahui oleh orangtua dan masyarakat (Sri Handayani, 2009).
Secara global, $40 \%$ dari semua kasus HIV/AIDS terjadi pada kaum muda 15-24 tahun. Perkiraan terakhir adalah setiap hari ada 7000 remaja yang terinfeksi HIV Jumlah kasus HIV di Indonesia yang dilaporkan hingga Maret 2007 mencapai 14.628 orang. Sedangkan kasus AIDS sudah mencapai 8.914 orang, separuh atau 57,4 \% dari kasus ini adalah kaum muda yang umurnya 15-29 tahun (Dwi Novita, 2011).

Hasil survei terakhir di 33 provinsi pada tahun 2008 yang dilakukan oleh Badan Koordinasi Keluarga Berencana (BKKBN) dilaporkan $63 \%$ remaja di Indonesia pada usia antara SMP dan SMA sudah melakukan hubungan seksual pranikah, ironisnya $21 \%$ diantaranya dilaporkan melakukan aborsi. Persentasi remaja yang melakukan hubungan seksual pranikah tersebut mengalami peningkatan dibanding tahun-tahun sebelumnya (Rahayu, 2013).

Sedangkan hasil Survei Komnas Perlindungan Anak yang dilakukan di 33 provinsi pada 2008, sebanyak 97\% remaja SMP dan SMA pernah menonton film porno. Mereka yang pernah berciuman, melakukan masturbasi, dan oral seks mencapai 93,7\%. Dan remaja SMP yang tidak perawan sebanyak $62,7 \%$, serta yang remaja melakukan pernah aborsi sebesar 21,2\% (Adhitya, 2012).

Minimnya informasi yang diterima remaja tentang kesehatan reproduksi dan seksual, menyebabkan rendahnya pengetahuan dan berpengaruh terhadap sikap remaja yang negatif terhadap masalah kesehatan reproduksi dan perilaku 
seksual. Faktor lingkungan juga memengaruhi sikap remaja dalam melakukan hubungan seks pranikah. Informasi yang semakin mudah diakses dari media massa cetak dan elektronik serta kondisi yang semakin permisif untuk melakukan seks pranikah seiring dengan norma yang semakin lemah pada masyarakat (Sri Handayani, 2009).

Hal ini juga dipengaruhi oleh anggapan masyarakat, khususnya orang tua yang masih menganggap tabu untuk membicarakan masalah seksualitas. Ironisnya di sisi lain remaja tidak menerima pendidikan kesehatan seksual yang benar dan bertanggung jawab. Mereka menerima informasi tentang seks justru dari sumber yang salah, bahkan menyesatkan, misalnya dari cerita teman, video porno, tayangan televisi dan film. Remaja dengan permasalahannyajustru menghadapi masalah ketika membutuhkan informasi dan pelayanan tentang kesehatan reproduksi (Rahayu, 2013).

Data dari BKKBN Indonesia tahun 2009 didapatkan 22,6\% remaja termasuk penganut seks bebas. Hal tersebut diakibatkan oleh kurangnya pengetahuan remaja tentang kesehatan reproduksi remaja, kurangnya pengawasan dari orang tua terhadap remaja dan adanya pergaulan bebas dikalangan remaja (Rahayu, 2013).

Berdasarkan penelitian Simanjorang tahun 2010 mengenai perilaku seksual remaja diberbagai kota besar di Indonesia, sekitar 20 hingga 30 persen remaja mengaku pernah melakukan hubungan seks pranikah. Sebanyak 62,7 \% anak SMP mengaku sudah tidak perawan. Sebanyak 21,2 \% remaja SMA mengaku pernah melakukan aborsi. Dari 2 juta wanita Indonesia yang pernah melakukan aborsi, 1 juta adalah remaja perempuan. Lebih lanjut Simanjorang menjelaskan, tingginya angka hubungan seks pranikah di kalangan remaja tersebut erat kaitannya dengan meningkatnya jumlah aborsi saat ini, serta kurangnya pengetahuan remaja akan reproduksi sehat. Jumlah aborsi saat ini tercatat sekitar 2,3 juta, dan 15-20 persen di antaranya dilakukan remaja. Hal ini pula yang menjadikan tingginya angka kematian ibu di Indonesia, dan menjadikan Indonesia sebagai negara yang angka kematian ibunya tertinggi di seluruh Asia Tenggara.

Berdasarkan hasil survei awal yang dilakukan peneliti melalui observasi, peneliti sering melihat siswa berpacaran bahkan datang ke sebuah klinik untuk tes kehamilan. Selain itu penulis melakukan wawancara kepada 10 siswa SMA Dharma Bakti Medan pada tanggal 7 Februari 2014, 7 orang yang tidak mengetahui tentang kesehatan reproduksi dan seks panikah. Mereka memperoleh informasi tentang kesehatan reproduksi dari orang tua, dan ada juga yang melalui buku porno, film porno, dan situs internet.

Berdasarkan uraian di atas, maka peneliti terdorong untuk melakukan penelitian tentang faktorfaktor yang behubungan dengan sikap remaja kelas XI terhadap hubungan seksual pranikah (Intercourse) di SMA Dharma Bakti Medan tahun 2014.

\section{Rumusan Masalah}

Uraian dalam latar belakang memberi dasar bagi peneliti untuk merumuskan masalah dalam penelitian ini adalah "faktor-faktor apa saja yang behubungan dengan sikap remaja kelas XI SMA Dharma Bakti Medan terhadap hubungan seksual pranikah (Intercourse)?"

\section{Tujuan Penelitian}

Untuk mengetahui faktor- faktor yang behubungan dengan sikap remaja kelas XI terhadap hubungan seksual pranikah (Intercourse) di SMA Dharma Bakti Medan tahun 2014.

\section{Hipotesis}

Hipotesis adalah sebuah pernyataan tentang sesuatu yang diduga atau hubungan yang diharapkan antara dua variabel atau lebih yang dapat diuji secara empiris. Hipotesis dalam penelitian ini adalah:

1. Ada hubungan pengetahuan kesehatan reproduksi dengan sikap remaja SMA terhadap hubungan seksual pranikah (Intercourse).

2. Ada hubungan peran orang tua dengan sikap remaja SMA terhadap hubungan seksual pranikah (Intercourse).

3. Ada hubungan peran media massa dengan sikap remaja SMA terhadap hubungan seksual pranikah (Intercourse).

\section{METODE PENELITIAN}

\section{Jenis dan Desain Penelitian}

Jenis penelitian ini adalah analitik dengan pendekatan desain cross sectional untuk mengetahui adanya hubungan antara dua variabel, sebab (independent) dan akibat (dependent). Dengan tujuan untuk mengetahui faktor-faktor yang berhubungan dengan sikap remaja terhadap hubungan seksual pranikah (intercourse) di SMA Dharma Bakti Medan 2014.

\section{Lokasi dan Waktu Penelitian \\ 2.1.Lokasi Penelitian}

Penelitian ini dilakukan di SMA Dharma

Bakti Medan tahun 2014 dengan alasan:

1. Dari hasil observasi, peneliti melihat banyak siswa setiap pulang sekolah bersama pasangannya masing-masing.

2. Adanya sepasang siswa SMA datang ke sebuah klinik untuk tes kehamilan.

3. Dari segi usia, remaja rentan terhadap perilaku seks pranikah.

\subsection{Waktu Penelitian}

Penelitian ini dilakukan mulai dari studi literatur dan pencarian judul pada bulan Desember 2013, kemudian dilanjutkan dengan penyusunan proposal, seminar proposal, penelitian dan seminar hasil penelitian hingga di bulan Juli 2014. 


\section{Populasi dan Sampel Penelitian}

Populasi dalam penelitian ini adalah remaja SMA Dharma Bakti Medan kelas XI tahun 2014 yakni sebanyak 60 orang.

Sampel dalam penelitian ini adalah seluruh dari populasi kelas XI SMA Dharma Bakti Medan 2014 atau total sampling yaitu sebanyak 60 orang.

\section{Jenis dan Cara Pengumpulan Data}

Jenis data dalam penelitian ini adalah data primer dan data sekuder. Pengumpulan data dengan menggunakan kuesioner untuk mengetahui faktorfaktor yang berhubungan dengan sikap remaja SMA terhadap hubungan seksual pranikah (intercourse).

Pengumpulan data primer dilakukan langsung oleh peneliti dengan menggunakan kuesioner lembar checklist dan pertanyaan terbuka sesuai dengan variabel. Peneliti datang ke sekolah responden. Sebelumnya peneliti memperkenalkan diri dan menjelaskan tujuan dari peneliti kepada responden. Sebelum responden mengisi kuesioner, terlebih dahulu peneliti menjelaskan cara mengisi kuesioner, kemudian memberikan kesempatan kepada responden untuk bertanya. Kemudian responden mengisi informat consent, dan mengisi sendiri kuesioner penelitian. Setelah selesai diisi, kuesioner dikumpulkan oleh peneliti dan diperiksa kembali.

\section{Pengolahan dan Analisis Data}

Data yang telah terkumpul diolah dengan cara komputer dengan langkah-langkah editing, coding, entering, cleaning dan tabulating. Analisis data dilakukan dengan analisis data univariate dan bivariate.

Analisis bivariate melihat beberapa faktor yang berhubungan dengan sikap remaja terhadap hubungan seks (intercourse) pranikah dengan menggunakan uji Chi-Square dan tingkat kemaknaan 0,05 atau $\alpha=0,05$ dengan derajat kepercayaan 95\%. Adapun rumus Chi-Square yang digunakan adalah:

$$
\begin{aligned}
\mathrm{X}^{2}=\left(\frac{0-E}{E}\right)^{2} & \\
& \text { dimana: } \\
& \mathrm{X}^{2}: \text { Chi-Square } \\
& \mathrm{O}: \text { Nilai hasil observasi } \\
& \mathrm{E}: \text { Nilai yang diharapkan }
\end{aligned}
$$

\section{HASIL DAN PEMBAHASAN}

\section{Analisa Data Univariat}

Analisa data univariat digunakan untuk melihat distribusi frekuensi dari variabel dependent dan variabel independent, yaitu:
Tabel 4.1.

Distribusi Frekuensi Sikap Remaja Terhadap Hubungan Seksual Pranikah (Intercourse) di SMA Dharma Bakti Medan Tahun 2014

\begin{tabular}{llc}
\hline Pengetahuan & Frekuensi & $\begin{array}{c}\text { Persentase } \\
(\%)\end{array}$ \\
\hline Baik & 43 & 71,67 \\
Kurang & 17 & 28,33 \\
\hline Jumlah & 60 & $100 \%$ \\
\hline Peran Orang Tua & & 78,33 \\
\hline Mendukung & 47 & 21,67 \\
Tidak mendukung & 13 & $100 \%$ \\
\hline Jumlah & 60 & \\
& & 33,33 \\
\hline Peran Media Massa & & 66,67 \\
\hline Berpengaruh & 2 & $100 \%$ \\
Tidak Berpengaruh & 40 & \\
\hline Jumlah & 60 & 93,3 \\
\hline Sikap & & 6,7 \\
\hline Positif & 56 & $100 \%$ \\
Negatif & 4 & \\
\hline Jumlah & 60 & \\
\hline
\end{tabular}

Berdasarkan tabel diatas diketahui bahwa responden yang memiliki pengetahuan kurang sebanyak 17 responden $(28,33 \%)$.

Berdasarkan tabel diatas diketahui bahwa peran orang tua responden yang tidak mendukung terhadap pemberian informasi tentang seksual pranikah sebanyak 13 responden $(21,67 \%)$.

Berdasarkan tabel diatas diketahui bahwa peran media massa yang berpengaruh terhadap perilaku seksual pranikah terhadap responden sebanyak 20 responden $(33,33 \%)$.

Berdasarkan tabel diatas diketahui bahwa responden yang memiliki sikap negatif sebanyak 4 responden $(6,7 \%)$.

\section{Analisis Data Bivariat}

Analisis data bivariat bertujuan untuk mengetahui ada tidaknya hubungan yang bermakna antara faktor-faktor yang berhubungan dengan sikap remaja terhadap hubungan seksual pranikah (intercourse) seperti pengetahuan, peran orang tua, dan peran media massa di SMA Dharma Bakti Medan Tahun 2014.

Pengujian analisis menggunakan uji chi-square dengan $\alpha=0,05$. Analisis ini dikatakan bermakna bila hasil analisis menunjukkan adanya hubungan yang bermakna secara statistik antara variabel, yaitu dengan nilai $\mathrm{p}$ value $<0,05$. 
Tabel 4.2.

Rekapitulasi Hasil Uji Chi-Square Faktor-Faktor yang Berhubungan dengan Sikap Remaja Kelas XI terhadap Hubungan Seksual Pranikah (Intercourse)

2.1 Pengetahuan

\begin{tabular}{lccccccc}
\hline \multicolumn{1}{c}{$\begin{array}{c}\text { Sikap Remaja } \\
\text { terhadap } \\
\text { Hubungan } \\
\text { Seksual Pranikah } \\
\text { (intercourse) }\end{array}$} & Total & p Value \\
\hline \multicolumn{7}{c}{ Positif } & Negatif \\
\hline Pengetahuan & F & \% & F & \% & F & \% & \\
Baik & 43 & 71,67 & 0 & 0 & 43 & 71,67 & 0,005 \\
Kurang & 13 & 21,67 & 4 & 6,66 & 17 & 28,33 & \\
\hline Total & 56 & 93,34 & 4 & 6,66 & 60 & 100 & \\
\hline
\end{tabular}

Berdasarkan tabel 4.5, dapat diketahui bahwa pengetahuan responden yang baik dan memiliki sikap positif sebanyak 43 responden $(71,67 \%)$, sedangkan yang memiliki pengetahuan kurang dan memiliki sikap positif sebanyak 13 responden $(21,67 \%)$. Responden yang memiliki pengetahuan baik dan sikap negatif tidak ada, memiliki pengetahuan kurang dengan sikap negatif sebanyak 4 responden $(6,67 \%)$.

Berdasarkan hasil uji chi-square menunjukkan bahwa nilai $\mathrm{p}$ value $=0,005(<0,05)$, yang artinya terdapat hubungan pengetahuan dengan sikap remaja terhadap hubungan seksual pranikah (intercourse) di SMA Dharma Bakti Medan.

\subsection{Peran Orangtua}

\begin{tabular}{|c|c|c|c|}
\hline & $\begin{array}{c}\text { Sikap Remaja } \\
\text { terhadap } \\
\text { Hubungan } \\
\text { Seksual } \\
\text { Pranikah } \\
\text { (Intercourse) } \\
\end{array}$ & Total & $\begin{array}{c}\mathbf{p} \\
\text { Value }\end{array}$ \\
\hline \multicolumn{4}{|c|}{ Positif Negatif } \\
\hline Peran Orang Tua & $\begin{array}{llll}\mathrm{F} & \% & \mathrm{~F} & \%\end{array}$ & F $\%$ & \\
\hline Mendukung & $4778,340 \quad 0$ & 4778,34 & +400 \\
\hline Tidak Mendukung & 46,66 & 1321,66 & 6,001 \\
\hline Total & $5693,3446,66$ & 60100 & \\
\hline
\end{tabular}

Berdasarkan hasil uji chi-square peran orang tua dengan sikap remaja terhadap hubungan seksual pranikah menunjukkan bahwa nilai $\mathrm{p}$ value $=0,001$ $(<0,05)$, yang artinya terdapat hubungan peran orang tua dengan sikap remaja terhadap hubungan seksual pranikah (intercourse) di SMA Dharma Bakti Medan.

\subsection{Peran Media Massa}

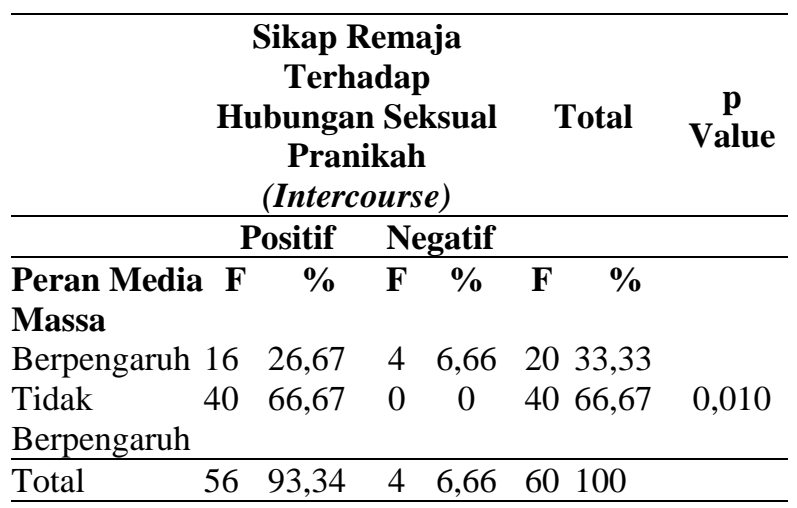

Berdasarkan hasil uji chi-square peran media massa dengan sikap remaja terhadap hubungan seksual pranikah menunjukkan bahwa nilai $\mathrm{p}$ value $=0,010$ $(<0,05)$, yang artinya terdapat hubungan peran media massa dengan sikap remaja terhadap hubungan seksual pranikah (intercourse) di SMA Dharma Bakti Medan.

\section{Pembahasan}

\section{Hubungan Pengetahuan Kesehatan Reproduksi Dengan Sikap Remaja Terhadap Hubungan Seksual Pranikah (Intercourse)}

Dari hasil analisa menunjukkan bahwa responden yang berpengetahuan baik sebanyak 43 responden $(71,67 \%)$ dan memiliki pengetahuan kurang sebanyak 17 responden $(28,33 \%)$.

Hasil uji statistik chi-square menunjukkan bahwa pengetahuan remaja tentang kesehatan reproduksi pada angka $\mathrm{p}$ value $=0,005(<0,05)$, artinya ada hubungan yang signifikan antara pengetahuan remaja tentang kesehatan reproduksi terhadap sikap remaja terhadap hubungan seksual pranikah (intercourse).

Dengan demikian hasil penelitian ini sejalan dengan penelitian Tut Wuri Prihatin (2007) bahwa semakin rendah pengetahuan remaja tentang kesehatan reproduksi maka semakin cenderung sikap remaja terhadap hubungan seksual pranikah (intercourse). Hal ini disebabkan tingkat pengetahuan siswa SMA yang masih kurang menjadikan mereka berada ketidaktahuan akan perkembangan dirinya. Sehingga dengan keterbatasan pengetahuan itulah, kadang membuat remaja mengambil sikap yang salah atas rangsang yang di terima. Pengetahuan remaja tentang kesehatan reproduksi sangat memengaruhi perilaku remaja untuk hidup sehat, khususnya yang terkait dengan kesehatan reproduksi.

Hal ini sesuai dengan pendapat Notoadmodjo (2010) bahwa pengetahuan atau kognitif merupakan domain yang sangat penting untuk terbentuknya tindakan seseorang (covert behaviour). Covert behaviour yang dimaksud adalah suatu respon seseorang terhadap stimulus dalam bentuk tertutup. Misalnya, seorang remaja tidak akan memutuskan melakukan hubungan seksual pranikah (intercourse), 
karena ia tahu bahwa berhubungan seksual pranikah (intercourse) dapat menyebabkan kehamilan yang tidak di inginkan dan penyakit seksual termasuk HIV/AIDS.

Menurut asumsi penulis berdasarkan hasil penelitian ini menunjukkan bahwa tingkat pengetahuan sangat berpengaruh dalam penentuan sikap remaja terhadap hubungan seksual pranikah (intercourse). Hal ini disebabkan karena kurangnya pengetahuan remaja mengenai kesehatan reproduksi menyebabkan remaja tidak mengetahui dampak dari hubungan seksual pranikah. Maka itu diperlukan pembekalan mengenai pengetahuan kesehatan reproduksi dan seksual, yang merupakan dasar bagi remaja agar perilaku remaja tidak menyimpang, khususnya terhadap perilaku hubungan seksual pranikah (intercourse).

\section{Hubungan Peran Orang Tua Dengan Sikap Remaja Terhadap Hubungan Seksual Pranikah (Intercourse)}

Berdasarkan penelitian diketahui bahwa peran orang tua responden yang mendukung terhadap pemberian informasi tentang seksual pranikah sebanyak 43 responden $(71,67 \%)$, sedangkan yang tidak mendukung sebanyak 17 responden $(28,33 \%)$.

Berdasarkan hasil dari analisis statistik uji chisquare bahwa peran orang tua pada angka signifikan $\mathrm{p}$ value $=0,001 \quad(<0,05)$. Hal ini menunjukkan adanya hubungan peran orang tua dengan sikap remaja terhadap hubungan seksual pranikah (intercourse).

Dengan demikian hasil penelitian ini sejalan dengan penelitian Tut Wuri Prihatin (2007) ada kecenderungan bahwa siswa yang tidak mendapat dukungan atau perhatian tentang kesehatan reproduksi dari orang tua akan cenderung bersikap mendukung terhadap hubungan seksual pranikah (intercourse).

Penelitian lain yang dilakukan oleh Soetjiningsih (2008) yang meneliti tentang faktorfaktor yang memengaruhi perilaku seksual pranikah pada remaja menunjukkan bahwa hubungan orang tua dan remaja mempunyai pengaruh besar terhadap perilaku remaja. Makin baik hubungan orang tua dengan remaja makin rendah perilaku seksual pranikah remaja.

Hal ini sesuai dengan pendapat Sarwono (2012) bahwa seks pranikah terakhir ini disebabkan karena orang tua tabu membicarakan seks dengan anaknya dan hubungan antara orang tua dengan anak sudah terlanjur jauh sehingga anak berpaling sumbersumber lain yang tidak akurat.

Idealnya pendidikan seks merupakan bagian proses belajar keseluruhan. Orang tua sebaiknya tidak menjelaskan seks sebagai topik formal yang dibahas saat seorang anak menginjak usia tertentu, tetapi sebaiknya menjadi bagian keseharian. Beberapa orang tua merasa bahwa mereka bukan orang yang tepat untuk memberikan pendidikan seks dengan sejumlah alasan. Beberapa diantara mereka merasa malu dan menganggap mereka kurang mampu dan tidak memiliki cukup informasi untuk menjawab berbagai pertanyaan seputar seks (Gilli, 2010).

Menurut asumsi penulis berdasarkan hasil penelitian ini menunjukkan bahwa peran orang tua sangat penting dan berpengaruh dalam penentuan sikap remaja terhadap hubungan seksual pranikah (intercourse). Peran orang tua dalam memberikan pengetahuan tentang seksual dan perhatian orang tua terhadap pergaulan remaja sangat dibutuhkan agar perilaku seksual remaja tidak terjadi. Peran orang tua dalam mendidik anak sangat menentukan pembentukan karakter dan perkembangan kepribadian anak. Selanjutnya hubungan komunikasi yang baik antara orang tua dan anak akan menciptakan saling memahami. Maka itu diperlukan komunikasi yang sesering mungkin antara orang tua dan anak terutama dalam membahas masalah-masalah kesehatan reproduksi saat anak memasuki usia remaja.

\section{Hubungan Media Massa Dengan Sikap Remaja Terhadap Hubungan Seksual Pranikah (Intercourse)}

Berdasarkan penelitian diketahui bahwa peran media massa yang memengaruhi responden terhadap hubungan seksual pranikah (intercourse) sebanyak 20 responden $(33,33 \%)$ dan yang tidak berpengaruh sebanyak 40 responden $(66,67 \%)$.

Hasil uji statistik chi-square menunjukkan bahwa peran media massa pada angka $\mathrm{p}$ value $=0,010$ $(<0,05)$, yang artinya ada hubungan yang signifikan antara peran media massa dengan sikap remaja terhadap hubungan seksual pranikah (intercourse).

Dengan demikian penelitian ini sesuai dengan yang dilakukan oleh Sarma Eko Natalia (2012) bahwa ada hubungan antara media massa dengan seks pranikah. Hal ini disebabkan oleh pengaruh media massa yang sering diadopsi remaja dalam kehidupan sehari-hari. Media yang dapat berperan dalam mentransformasikan perubahan nilai seksualitas yaitu dari hiburan program televisi yang menampilkan tayangan pornografi dan pendidikan seks yang yang kurang tepat. Dari hasil observasi yang dilakukannya, remaja yang menonton film berkebudayaan barat membuat mereka menjadikan seks itu menyenangkan.

Penelitian ini juga mendukung dalam Penelitian Tut Wuri (2007) bahwa ada hubungan yang signifikan antara peran media massa yang disampaikan secara terbuka dalam bentuk pesan sederhana sampai yang sangat kompleks akan menambah pengetahuan seseorang, serta akan memengaruhi seseorang dalam bersikap untuk mengambil keputusan dan bertindak dengan cara positif. Hal tersebut berhubungan dengan sikap remaja terhadap hubungan seksual pranikah (intercourse).

Seks pranikah dipengaruhi oleh informasi yang semakin mudah diakses dari media massa cetak dan elektronik serta kondisi yang semakin permisif untuk melakukan seks pranikah seiring dengan norma yang semakin lemah pada masyarakat (Sri Handayani, 2009). 
Hal ini juga dipengaruhi oleh anggapan masyarakat, khususnya orang tua yang masih menganggap tabu untuk membicarakan masalah seksualitas. Ironisnya di sisi lain remaja tidak menerima pendidikan kesehatan seksual yang benar dan bertanggung jawab. Mereka menerima informasi tentang seks justru dari sumber yang salah, bahkan menyesatkan, misalnya dari cerita teman, video porno, tayangan televisi dan film. Remaja dengan permasalahannyajustru menghadapi masalah ketika membutuhkan informasi dan pelayanan tentang kesehatan reproduksi (Rahayu, 2013).

Menurut asumsi penulis berdasarkan hasil penelitian ini menunjukkan bahwa peran media massa sangat berpengaruh terhadap sikap remaja terhadap hubungan seksual pranikah (intercourse). Dari hasil penelitian menunjukkan bahwa semakin sering remaja berhubungan dengan media massa atau mencari informasi tentang seksual melalui media, semakin cenderung remaja melakukan hubungan seksual pranikah (intercourse). Keterpaparan remaja terhadap pornografi dalam bentuk bacaan berupa buku porno, melalui film porno semakin meningkat. Sementara konsultasi seks yang diberikan melalui media cetak dan elektronik yang disebut sebagai pendidikan seks, penayangan film tertentu di televisi sering menyebabkan salah persepsi/ pemahaman yang kurang tepat terhadap kesehatan reproduksi sehingga remaja mencontoh perilaku seksual dari media yang mereka terima.

\section{KESIMPULAN DAN SARAN}

\section{Kesimpulan}

Berdasarkan hasil penelitian mengenai faktorfaktor yang berhubungan dengan sikap remaja terhadap hubungan seksual pranikah (intercourse) di SMA Dharma Bakti Medan tahun 2014 dapat diambil kesimpulan sebagai berikut:

a. Ada hubungan pengetahuan kesehatan repsoduksi dengan sikap remaja terhadap hubungan seksual pranikah (intercourse). Hal ini disimpulkan bardasarkan hasil uji statistik chi-square menunjukkan bahwa pengetahuan remaja tentang kesehatan reproduksi pada angka signifikan $\mathrm{p}$ value $=0,005(<0,05)$, dengan demikian tidak terdapat kesenjangan antara hasil penelitian dengan teori.

b. Ada hubungan peran orang tua dengan sikap remaja terhadap hubungan seksual pranikah (intercourse). Hal ini disimpulkan bardasarkan hasil uji statistik chi-square menunjukkan peran orang tua pada angka signifikan $\mathrm{p}$ value $=0,001 \quad(<0,05)$, dengan demikian tidak terdapat kesenjangan antara hasil penelitian dengan teori.

c. Ada hubungan peran media massa dengan sikap remaja terhadap hubungan seksual pranikah (intercourse). Hal ini disimpulkan bardasarkan hasil uji statistik chi-square menunjukkan bahwa peran media massa pada angka signifikan $\mathrm{p}$ value $=0,010(<0,05)$, dengan demikian tidak terdapat kesenjangan antara hasil penelitian dengan teori.

\section{Saran}

Bardasarkan hasil dan kesimpulan dari data yang diperoleh, saran yang dapat penulis sampaikan dalam penelitian ini adalah sebagai berikut:

a. Diharapkan kepada pihak sekolah dapat menjadikan penelitian ini sebagai pedoman untuk meningkatkan pemberian ataupun pendidikan mengenai informasi kesehatan reproduksi khususnya tentang sex education bagi remaja di sekolah. Misalnya melalui metode peer education yang bersifat youth freendly (ramah terhadap remaja), artinya tidak hanya memberi materi melalui proses belajar mengajar di kelas, tetapi dikembangkan dengan metode lain seperti pemasangan mading, kesenian sekolah atau drama teater, dan lain - lain, yang memuat materi dasar kesehatan reproduksi yang proporsional yang mencangkup pemahaman remaja tentang perubahan fisik anak laki - laki dan perempuan saat menjadi remaja, mengenal masa subur, terjadinya proses kehamilan, metode kontrasepsi $\mathrm{KB}$, pencegahan penyakit menular seksual, perilaku seksual yang sehat dan bertanggung jawab, serta akibat dari kehamilan tak dikehendaki.

b. Diharapkan kepada remaja khususnya siswa kelas XI SMA Dharma Bakti Meda tahun 2014 agar lebih memperdalam ilmu kesehatan reproduksi terutama tentang dampak dari perilaku seksual pranikah melalui sumber informasi yang terpercaya dan meningkatkan komunikasi dengan orang tua terutama dalam membahas masalah kesehatan reproduksi agar remaja dapat memiliki pengetahuan yang baik tentang kesehatan reproduksi khususnya tentang seksual.

\section{DAFTAR PUSTAKA}

Arikunto, S., 2010. Prosedur Penelitian. Jakarta: Rineka Cipta.

Boyke., 2013. Problema Seks dan Solusinya. Jakarta: Bumi Aksara.

Gilli., 2010. Buku Ajar Kesehatan Reproduksi Wanita. Jakarta: EGC.

Irianto, K., 2013. Permasalahan Seksual. Bandung: Yrama Widya.

Kholid, A., 2012. Promosi Kesehatan. Jakarta: Rajagrafindo Persada.

Manuaba, dkk., 2009. Memahami Kesehatan Reproduksi Wanita. Edisi 2. Jakarta: EGC.

Notoadmodjo, S., 2010. Metodologi Penelitian Kesehatan. Jakarta: SalembaMedika.

2010. Promosi Kesehatan Teori dan Aplikasi. Jakarta: Rineka Cipta.

Nugroho, T., 2010. Buku Ajar Ginekologi. Yogyakarta: Nuha Medika. 
Pieter, H.Z. dan Lubis, N., 2010. Pengantar Psikologi dalam Keperawatan. Edisi 1. Jakarta: Kencana.

Pinem, S., 2009. Kesehatan Reproduksi dan Kontrasepsi. Jakarta: Trans Info Media.

Politeknik Kesehatan Depkes Jakarta I. 2010. Kesehatan Remaja: Problem dan Solusinya. Jakarta: Salemba Medika.

Politeknik Kesehatan Kemenkes Medan. 2012. Panduan Penyusunan Karya Tulis Ilmiah.

Sarwono, S., 2012. Psikologi Remaja. Jakarta: Raja Grafindo Persada.

Suryani, E. dan Widyasih, H., 2010. Psikologi Ibu dan Anak. Yogyakarta: Fitramaya.

Wawan, A. dan Dewi., 2011. Teori dan Pengukuran Pengetahuan, Sikap, dan Perilaku Manusia. Yogyakarta: Nuha Medika.

Widyastuti, dkk., 2009. Kesehatan Reproduksi. Yogyakarta: Fitramaya.

Wuryani, S.E., 2008. Pendidikan Seks untuk Keluarga. Jakarta: Indeks.

Yusrawati., 2011. Diktat Biostatistika. Medan: Politeknik Kesehatan Medan Jurusan Kebidanan.

BKKBN. 2011. Kajian Profil Penduduk Remaja. Available at: www.bkkbn.go.id/.../Hasil\%20Penelitian/.../Kaji an\%20Profil \%20Penduduk\%20Remaja\%20(10 $\% 20-\% 2024 \% 20 \mathrm{t} . \quad$ [ Accessed 27 Desember 2013].

Handayani. S., 2009. Efektivitas Metode Diskusi Kelompok dengan dan tanpa Fasilitator pada Peningkatan Pengetahuan, Sikap dan Motivasi Remaja tentang Perilaku Seks Pranikah. Available at: http://berita-kedokteran-

masyarakat.org/index.php/BKM/article/view/172. [Accessed 5 Januari 2014].
Prasetya. 2011. Dampak Seks Pranikah bagi Kesehatan. Available at: http://www.lensaindonesia.com/2013/02/11/dam pak-seks-pra-nikah-bagi-kesehatan.html. [Accessed 12 Januari 2014].

Rahayu. N., et al., 2013. Pengaruh Kegiatan Penyuluhan dalam Pelayanan Kesehatan Peduli Remaja (PKPR) terhadap Pengetahuan dan Sikap Remaja tentang Seks Pranikah di SMA N 1 Lubuk Pakam Kabupaten Siak Sri Indrapura Tahun 2013. Available at: jurnal.usu.ac.id/index.php/gkre/article/download 13633/1907 [Accessed 23 Desember 2013].

SDKI. 2012. Kesehatan Reproduksi Remaja. Available at www.bkkbn.go.id/.../Hasil\%20Penelitian/SDKI $\% 202012 /$. [Accessed at 27 Desember 203].

Soetjiningsih., 2008. Faktor-faktor yang Mempengaruhi Perilaku Seksual Pranikah pada Remaja. Available at: http://lib.ugm.ac.id/digitasi/upload/824_RD09060 04.pdf. [Accessed 5 Januari 2014].

Tut Wuri., 2007. Analisis Faktor-faktor yang berhubungan dengan Sikap Siswa SMA terhadap Hubungan seksual (Intercouse) Pranikah di Kota Sukoharjo Tahun 2007. Available at: eprints.undip.ac.id/18061/1/Tut Wuri Prihatin.p df. [Accessed at 23 Desember 2013].

Yuliantini. H., 2012. Tingkat Pengetahuan HIV/AIDS dan Sikap Remaja terhadap Perilaku Seksual Pranikah di SMA " $X$ ” Jakarta Timur. Available at: $\quad$ lontar.ui.ac.id/file?file=digital/20312663S\%2043157...full\%20text.pdf

[Accessed 23 Desember 2013]. 